\title{
Life Cycle Management and Circular Economy Challenges for the Textile Sector: Session Wrap Up
}

\author{
Keith James and Julian Lings
}

\begin{abstract}
This session demonstrated the added-value of applying Life Cycle Assessment to address different types of issues related to the textiles sector. Each of the four presentations in the session was based on case-studies, also highlighted the important challenges to be faced regarding methodological issues and market issues, to make LCA fully efficient for the sector. In particular, it has been demonstrated that one of the main concern for the sector is toxicity assessment, which is currently limited due to lack of data inducing weaknesses in characterisation of substances contributing to this impact. It also has been shown that in the objective of developing circular models, multiple issues must be addressed simultaneously. For example, to increase recycling of clothing unsuitable for reuse, markets must be developed at the same time that infrastructure is developed and collection mechanisms are put in place. It must also be tackled in a sustainable way, supported by Life Cycle Assessment and Life Cycle Costing.
\end{abstract}

\section{Introduction}

The textiles sector faces a number of challenges. Clothing is the eighth largest sector in the EU ranking of household expenditure, but the fourth largest when it comes to environmental impacts [1]. Only transport, housing and food have greater impacts. As part of the European Clothing Action Plan (ECAP), a Life+ funded programme, WRAP estimate that over 6.4 million tonnes of clothing were purchased across the EU in 2015, and that this clothing is associated with 195 million tonnes $\mathrm{CO}_{2} \mathrm{eq}, 46$ billion $\mathrm{m}^{3}$ of water and 11 million tonnes of waste across the whole life cycle of the clothing.

K. James $(\square)$

WRAP, Banbury, UK

e-mail: Keith.James@wrap.org.uk

J. Lings

The North Face, Stabio, Switzerland

(C) The Author(s) 2018

E. Benetto et al. (eds.), Designing Sustainable Technologies,

Products and Policies, https://doi.org/10.1007/978-3-319-66981-6_7 
However, these are just some of the challenges faced. At the LCM2017 conference, Sandra Roos from the Swedish research institute Swerea presented the toxicity footprint of Swedish Clothing Consumption [2]. Many environmental organizations have reported on the damage caused by dyeing and finishing of textiles, both humans and the environment. In addition, the use of pesticides in cotton production accounts for $25 \%$ of global pesticide use, despite the crop occupying only $2 \%$ of agricultural land. Roos et al. attempted to compare the toxicity impact of these three different stages. As part of the research Roos et al. identified only 7 out of 58 LCA studies focussed on textiles had included textile chemicals in the inventory, and of these only 4 studies had also developed LCIA to match these flows. It was therefore necessary to create additional inventories and develop characterisation factors. Characterisation factors are complex to develop; a data source selection strategy is recommended in order to keep consistency. The factors developed were combined with data on Swedish clothing consumption. The results suggest that eco-toxicity associated with wet treatment (dyeing and finishing) was one order of magnitude higher than for the cotton cultivation (all toxicity in the fibre production stems from cotton cultivation). This shows the value of Life Cycle Management and the need to understand life cycle stages to address priority issues.

\section{Framing and Responding to the Challenge}

The challenges may be framed and addressed in terms of a number of initiatives, such as the United Nations Sustainable Development Goals, the European Commission's Circular Economy Package, Product Environmental Footprint Initiative, and EU Garment Initiative, as well as Action Plans led by National Governments and Industry Associations.

Within each of these frameworks, different options are open to businesses across the clothing value chain. A key challenge is selecting the right strategy for the business, their products and their customers: they may consider increased durability, recyclability, or look more deeply at their business model to consider options such as subscription services, repair and advice on caring for clothing. Companies such as VF Corporation are seeking to address these challenges. Founded in 1899, $\mathrm{VF}$ is one of the world's largest apparel, footwear and accessories companies, incorporating over 30 brands such as North Face. Their sustainability mission is to protect our outdoor playgrounds and communities through the design and development of environmentally and socially responsible products and business practices. Through Life Cycle Assessment (LCA) they have determined that the majority of their environmental impact comes from materials processing, and product manufacturing. The North Face is now shifting the business away from finite materials, eliminating supply chain waste and developing closed loop solutions for post-consumer waste. 
Life Cycle Management can help to realise the potential environmental benefits of such changes and prioritise actions. Roos' work also identifies that, for climate change potential, there is little contribution from activity within Sweden, with the life cycle impacts dominated by yarn spinning, weaving and dyeing. However, in the UK, consumer care contributes significantly to the overall footprint. Regionalised tools, such as the ECAP Footprint tool, are therefore required to help businesses to make such changes based on representative information relevant for the appropriate supply chain and consumer.

Life Cycle Management is important at every decision point in the life cycle of clothing. Fierro [3] and Holmquist [4] both presented the role of life cycle management in choosing a raincoating, substituting out the most hazardous chemicals. Any substitution has the potential to lead to regrettable substitutions, and therefore needs to be holistic, and also ensure that the product functionality is maintained. Durable water and oil repellents (DWOR) are textile finishings which impart water (and oil) repellency, with three main chemistry types. Whilst the Long-chain perand polyfluoroalkyl substances (PFAS) are being phased out, the alternatives also give rise to emissions of hazardous substances.

Hanna Holmquist presented an ecotoxicity assessment of the three main chemistry types showing little difference between them, though USEtox does not capture PFAS hazards. A life cycle perspective however reveals that the ecotoxicity associated with the DWOR is dwarfed by the fabric manufacture, and the fabric and the membrane is important for Global Warming Potential. Change in the length of the product life therefore have the potential for large effects on the total potential ecotoxicity impact. This can be achieved through re-impregnation of DWOR, which has a relatively small contribution to ecotoxicity potential.

Julio Fierro presented the Life MIDWOR project and draft LCA results. DWORs have a complex structure (comb-like) with several side chains. Over time, perfluorinated chains are severed from DWOR structure and released to the environment. Consequently, PFC degradation compounds can be detected all over the world, with most originating from production sites. Their stability means the compounds can bio-accumulate, with concerns relating to potential mutagenic, carcinogenic and reprotoxic impacts. The MIDWOR project explores six different textile industries with a common finishing process. Two finishing products were considered: Short-chain DWOR and Silicone based DWOR. The draft LCA results suggest little difference between these when the impact of fabric production is also included, with differences only becoming apparent when considering finishing only. This is in line with Holmquist's conclusions.

In order to apply life cycle management principles to DWOR there is a need for further information on their production. The composition of DWORs is not always specified in Safety datasheets and is often a trade secret. These barriers must be overcome for life cycle management principles to be applied. In addition, life cycle methodologies do not reflect the impact of PFCs. Only the Ecological Scarcity methodology was identified as including the impact of PFCs, and this yields notably different results to other methodologies based on the same data. 
All frameworks identify a need to address multiple issues. Often these must be addressed simultaneously. For example, to increase recycling of clothing unsuitable for reuse, markets must be developed at the same time that infrastructure is developed, collection mechanisms are put in place and public communications occur; if any three of these occur without the fourth, then the system will not be able to change. Projects such as ECAP and RESYNTEX are seeking to address these complex challenges.

Harbi [5] presented the RESYNTEX project which addresses two objectives of a circular economy; to reduce waste and to reduce resource extraction through use of textile waste to generate secondary raw materials. RESYNTEX is a partnership between 20 organisations funded by Horizon 2020 to take the clothing currently sent to landfill or incineration and, through biochemical processing, generate resin, bioethanol, bottle-grade PET granulate and value added chemicals. The project will use both LCA and Life Cycle Costing (LCC) to assess the performance of the process, and will further explore biochemical treatment to understand the different contributions and optimise performance. The RESYNTEX system will also be compared with reference systems and global textile/chemical markets will be assessed.

\section{Future Perspectives}

The conference session achieved broad consensus on the scale of the challenge for the textiles sector, and the growth of these challenges if action is not taken. There is a recognition of the value of life cycle management in guiding organisations, and the need for fundamental change across the value chain.

There was consensus in the conference session that there is a need to consider multiple environmental issues, and that there are data barriers to understanding toxicity impacts. However, these are surmountable. There is a need for characterisation factors to reflect properly environmental impact of conventional and alternative DWORs and improvements in knowledge about DWOR production and composition. There is also a need to address multiple market challenges to realise a systemic change in the way clothes are managed at end of life and used as raw materials again. Further research and development in this area will be required.

\section{References}

1. EEA, Environmental Indicators Report 2014, pp 26, 114, 115.

2. Roos S, Arvidsson R, Jönsson C, Calculating the toxicity footprint of Swedish clothing consumption, LCM 2017 conference, Luxembourg, 2017.

3. Fierro J, Martínez C, Environmental analysis of the best available finishing products to provide water, oil and dirt repellency in the textile sector - A Life Cycle Assessment approach, LCM 2017 conference, Luxembourg, 2017. 
4. Holmquist H, Roos S, Jönsson C, Peters G, Choosing a rain coating - Life Cycle Assessment to guide substitution of hazardous durable water repellent chemistry, LCM 2017 conference, Luxembourg, 2017.

5. Magaud V, Dauriat A, Mzikian P, Troppenz V, Harbi S, Recycling textile waste into secondary material: Experience from the innovative RESYNTEX project using circular economy concepts, LCM 2017 conference, Luxembourg, 2017.

Open Access This chapter is licensed under the terms of the Creative Commons Attribution 4.0 International License (http://creativecommons.org/licenses/by/4.0/), which permits use, sharing, adaptation, distribution and reproduction in any medium or format, as long as you give appropriate credit to the original author(s) and the source, provide a link to the Creative Commons license and indicate if changes were made.

The images or other third party material in this chapter are included in the chapter's Creative Commons license, unless indicated otherwise in a credit line to the material. If material is not included in the chapter's Creative Commons license and your intended use is not permitted by statutory regulation or exceeds the permitted use, you will need to obtain permission directly from the copyright holder. 